\title{
Biochemical and molecular characterization of a new pullulan producer Rhodosporidium paludigenum PUPY-06
}

\author{
RS Singh*, Navpreet Kaur \\ Department of Biotechnology, Carbohydrate and Protein Biotechnology Laboratory, Punjabi University, Patiala, Punjab, India.
}

\begin{tabular}{|c|c|}
\hline $\begin{array}{l}\text { Article history: } \\
\text { Received on: August } 12,2017 \\
\text { Accepted on: October } 23,2017 \\
\text { Available online: January } 17,2018\end{array}$ & $\begin{array}{l}\text { Pullulan is a random coil glucan polymer produced by Aureobasidium pullulans. It is one of the commercially } \\
\text { promising biopolymers frequently used in pharmaceutical, food and cosmetics industries. The aim of present study } \\
\text { was to isolate an efficient fungal strain producing melanin-free pullulan. The fungal strains were isolated from fresh } \\
\text { and decaying leaves of plants and screened for pullulan production. Fungal isolate PUPY- } 06 \text { was the best producer }\end{array}$ \\
\hline $\begin{array}{l}\text { Key words: } \\
18 \mathrm{~s} \text { rRNA, } \\
\text { Nuclear magnetic resonance, } \\
\text { Phylogenetic tree, } \\
\text { Pullulan, } \\
\text { Rhodosporidium paludigenum, } \\
\text { Shake-flask fermentations. }\end{array}$ & $\begin{array}{l}\text { of pullulan }(2.12 \%, \mathrm{w} / \mathrm{v}) \text {. Morphological studies revealed the oval and cylindrical shape of its cells, budding and } \\
\text { presence of septate as well as pseudohyphae. Colonies of the isolate on agar plate cultures were beige-to-orange } \\
\text { colored with smooth, mucoid, and butyrous texture. Morphological and biochemical characterization established } \\
\text { the fungal isolate as Rhodosporidium sp. } 18 \mathrm{~s} \text { rRNA sequencing, and phylogenetic analysis revealed the isolate to be } \\
\text { Rhodosporidium paludigenum. Fourier-transform infrared spectroscopy and nuclear magnetic resonance of crude } \\
\text { pullulan confirmed its structural characteristics. Maximum production of pullulan was achieved after } 7 \text { days of } \\
\text { cultivation in shake-flask fermentations. Agitation mode of cultivation supported the higher production of pullulan in } \\
\text { comparison to the stationary mode. } R \text {. paludigenum PUPY-06 was found as a novel pullulan-producing strain. This } \\
\text { is a first report on pullulan production by } R \text {. paludigenum PUPY-06. }\end{array}$ \\
\hline
\end{tabular}

\section{INTRODUCTION}

Biopolymers are polymeric biomolecules produced by living organisms. Microbial biopolymers with interesting industrial properties can act as a promising alternative for existing polymers. Microorganisms synthesize intracellular, structural, and extracellular biopolymers based on their morphological localization, i.e., polysaccharides, polyesters, and proteins. Pullulan is one of the commercially promising microbial biopolymers. Structurally, it is a random coil glucan polymer produced mainly by the yeast-like fungus Aureobasidium pullulans. Apart from A. pullulans, other pullulan-producing microorganisms are Tremella mesenterica [1], Cytaria harioti [2], Cyttaria darwinii [3], Rhodotorula bacarum [4], Cryphonectria parasitica [5], Teloschistes flavicans [6], and C. parasitica [7,8]. Commercially, pullulan is produced from $A$. pullulans. Some strains of $A$. pullulans generate melanin along with the pullulan production during their growth cycle and are known as black yeast. Melanin is a dark green-to-black colored pigment produced by the microbial cells commonly during the stationary phase of growth. The presence of melanin in the media gives

*Corresponding Author

RS Singh

Department of Biotechnology,

Carbohydrate and Protein Biotechnology Laboratory,

Punjabi University, Patiala, Punjab, India.

Tel.: +91 175304 6262; Fax: +91 1752283073.

Email: rssingh11@lycos.com an undesired color to the final product, and its separation also adds to the cost of pullulan downstream processing [9]. A novel melaninfree pullulan-producing strain of $A$. pullulans has been reported from phylloplane of Ficus sp. [10]. Henceforth, the isolation of melaninfree strains is a prerequisite nowadays for cost-effective production of pullulan captivating the industrial aspects too.

Pullulan is a linear and unbranched exopolysaccharide consisting of $\alpha$ - $(1 \rightarrow 4)$ triglucosides $\left(G_{3}\right)$, i.e., $[\rightarrow 6)-\alpha$-D-glucopyranosyl- $(1 \rightarrow 4)-\alpha-$ D-glucopyranosyl- $(1 \rightarrow 4)-\alpha$-D-glucopyranose- $(1 \rightarrow]_{n}$ with molecular formula $\left(\mathrm{C}_{6} \mathrm{H}_{10} \mathrm{O}_{5}\right)_{\mathrm{n}}$. Alternatively, pullulan structure may also consist of repeating units of panose, isopanose, maltose, isomaltose, and maltotetraose [9]. Pullulan has unique physical and chemical properties due to the coexistence of $\alpha-(1 \rightarrow 4)$ and $\alpha-(1 \rightarrow 6)$ glycosidic linkages. It is soluble in hot and cold water but non-soluble in organic solvents except dimethylformamide and dimethylsulfoxide $[11,12]$. It is biodegradable, tasteless, and odorless. The maximum temperature tolerance of pullulan is $250-280^{\circ} \mathrm{C}$ with an optical rotation of 192 in $1 \mathrm{~g} / \mathrm{dL}$ solution [13], and the molecular weight is in the range of 45-600 kDa.

Pullulan has a wide range of applications in food and pharmaceutical industries $[14,15]$. It can be used as non-polluting wrapping material for food supplements [9]. It can be molded in edible, biodegradable, oxygen impermeable, and water-soluble films [16]. Moreover, it can act as a binder, lubricant, gelling agent [9], denture adhesive, emulsifier, and stabilizer for various food products [17]. It has also been used 
in many oral care products, for example, Listerine pocketpack oral care strips [13] and maltotriose syrup preparation [18-20]. Biomedical applications of pullulan include drug delivery, gene delivery [21,22], tissue engineering [23], vaccination [24,25], medical imaging [26], plasma expander [27], molecular chaperones [28], and film forming [29].

The aim of present study was to isolate melanin-free pullulan-producing fungal strains. A melanin-free pullulan-producing fungal strain of Rhodosporidium paludigenum was isolated from decaying leaves of Ficus lacor. R. paludigenum is a teleomorphic fungus which belongs to subkingdom Dikarya, division Basidiomycota, Pucciniomycotina [30], class Microbotryomycetes [31], order Sporidiobolales [32], and family Sporidiobolaceae [33]. It is included in the Incertae sedis genera of Sporidiobolales. The isolate was identified on the basis of biochemical and molecular characterization. It was used for the production of pullulan in shake-flask fermentations. Literature survey reveals that this is the first report on pullulan production from $R$. paludigenum. $R$. paludigenum might be a potential candidate for the production of pullulan at industrial scale.

\section{MATERIALS AND METHODS}

\subsection{Isolation and Maintenance of Fungal Cultures}

Fresh and decaying plant leaves were collected from Botanical Gardens, Punjabi University, Patiala, Punjab, India. Leaf samples were subjected to a selective enrichment procedure for isolation of fungal cultures [34]. The leaves were soaked in sterile distilled water $(25 \mathrm{~mL})$ for 3 days at $25^{\circ} \mathrm{C}$. Each sample $(1 \mathrm{~mL})$ was transferred separately in Erlenmeyer flasks containing pre-sterilized minimal salts media $(25 \mathrm{~mL})$ containing $(\%, \mathrm{w} / \mathrm{v})$ : Sucrose 1 ; diammonium hydrogen phosphate 0.1 ; sodium chloride 0.05 ; magnesium sulfate hydrate 0.005 ; dipotassium hydrogen phosphate 0.2 ; ferrous sulfate, manganese sulfate, and zinc sulfate 0.001 each. The medium was also supplemented with $1 \mathrm{mg}$ of chloramphenicol, and its $\mathrm{pH}$ was adjusted to 4.0. Flasks were incubated at $25^{\circ} \mathrm{C}$ for 2 days, under agitation $(150 \mathrm{rpm})$ on a rotary shaker (CIS-24PLUS, REMI, India). The spreading of fungal cells enrich suspension was carried out on agar plates containing the same medium and incubated at $25^{\circ} \mathrm{C}$ for 4 days. Independent fully grown colonies were picked up and maintained on potato dextrose agar (PDA) slants and stored at $4{ }^{\circ} \mathrm{C}$ for further experimentation. All the isolates were grown on PDA plates for 12 days to observe the generation of blue-to-black colored pigments (melanin).

\subsection{Screening of Fungal Isolates for Pullulan Production}

\subsubsection{Inoculum preparation}

Inoculum was prepared by cultivating all fungal isolates individually in a medium containing $(\%, \mathrm{w} / \mathrm{v})$ : Beef extract 0.8 ; yeast extract 0.5 ; glucose 0.1 ; and adjusted to $\mathrm{pH}$ 5.5. The cultivation was carried out at $25^{\circ} \mathrm{C}$ for $48 \mathrm{~h}$, under agitation $(150 \mathrm{rpm})$.

\subsubsection{Production of pullulan by fungal isolates}

All the fungal isolates were screened for pullulan production in shakeflask fermentations. The production medium $(100 \mathrm{~mL})$ in Erlenmeyer flasks containing $(\%, \mathrm{w} / \mathrm{v})$ : Sucrose 5 ; yeast extract 0.2 ; sodium chloride 0.1 ; dipotassium hydrogen phosphate 0.5 ; magnesium sulfate hydrate 0.02 ; and adjusted to $\mathrm{pH} 6.0$ was inoculated with $5 \%(\mathrm{v} / \mathrm{v})$ of 2 days old culture of each isolate. The Erlenmeyer flasks were incubated at $25^{\circ} \mathrm{C}$ for 7 days, under agitation $(150 \mathrm{rpm})$. Thereafter, the culture broth was analyzed for pullulan quantification.

\subsection{Identification of Most Efficient Pullulan-producing Fungal Isolate}

\subsubsection{Morphological studies}

Identification of the fungal isolate PUPY-06 was done by studying its micro- and macro-scopic characteristics as described by Fell and Tallman [35]. Macromorphology involving colonial characteristics of fungal isolate on PDA plates, i.e., color, texture, appearance, and margin was investigated. In micromorphological studies, cells shape, basidia, teliospores types of budding, filament, basidia septation, and catenate-solitary cells were observed. Slides were prepared from actively growing colonies of fungal isolate PUPY-06 on PDA plates and stained with methylene blue dye. Light photomicrographs of fungal isolate PUPY-06 were obtained by Leica DM 4000 B LED microscope fitted with a digital camera (DFC450C, Germany) using Leica application suite version 4.2.

\subsubsection{Physiological and biochemical characterization}

\subsubsection{Fermentation of sugars}

Fungal isolate PUPY-06 was investigated for its ability to ferment various sugars by Durham tube method using fermentation basal medium as described by Wickerham [36]. Fermentation basal medium was supplemented with yeast extract $(4.5 \%, \mathrm{w} / \mathrm{v})$ and peptone $(7.5 \%, \mathrm{w} / \mathrm{v})$. Bromothymol blue was also added to the fermentation medium. Durham tubes were placed in inverted position in test tubes containing fermentation medium. The final concentration of each sugar in sterilized medium was maintained to $2 \%(\mathrm{w} / \mathrm{v})$ by adding filter sterilized sugar solution. Test tubes were inoculated with $100 \mu \mathrm{L}$ of 2 days old culture and incubated at $25^{\circ} \mathrm{C}$ for 10 days. The change in color of medium and presence of gas in Durham tubes were observed.

\subsubsection{Assimilation of carbon and nitrogen compounds}

Yeast nitrogen base medium (having carbon compound 5\%,w/v) and yeast carbon base medium (having nitrogen compound $0.108 \%$, w/v) were used to check the assimilation of carbon and nitrogen compounds by fungal isolate PUPY-06 as described by Wickerham [36]. Test tubes containing sterilized media were inoculated with $100 \mu \mathrm{L}$ of 2 days old culture and incubated at $25^{\circ} \mathrm{C}$ for 7 days. Test tubes were observed visually for a positive or negative growth of culture using each carbon and nitrogen source individually.

\subsubsection{Formation of extracellular amyloid compounds (starch formation)}

Fungal isolate PUPY-06 was examined for the formation of starchlike extracellular amyloid compounds by Lugol's iodine test. Lugol's iodine solution was prepared by dissolving $1 \mathrm{~g}$ iodine and $2 \mathrm{~g}$ potassium iodide in $300 \mathrm{~mL}$ of demineralized water. The isolate was grown in a test tube containing yeast nitrogen base medium with glucose $(3 \%, \mathrm{w} / \mathrm{v})$ at $25^{\circ} \mathrm{C}$ for 7 days. Two drops of diluted Lugol's iodine solution were added to the culture medium, and change in color (blue to green) was observed as a positive response.

\subsubsection{Acetic acid production}

Acetic acid production was determined by streaking fungal isolate PUPY-06 onto agar plates of Custer's chalk medium containing $(\%, \mathrm{w} / \mathrm{v})$ : Glucose 5 and calcium carbonate 0.5 [37]. The agar plates were incubated at $25^{\circ} \mathrm{C}$ and observed for clear zone around the grown colonies.

\subsubsection{Urea hydrolysis}

Fungal isolate PUPY-06 was investigated for urea hydrolysis [38] using Christensen's urea agar medium containing $(\%, w / v)$ : Peptone 0.1 ; glucose 0.1 ; sodium chloride 0.5 ; potassium dihydrogen phosphate 0.2; agar 1.5; phenol red 0.0012; and $\mathrm{pH}$ was adjusted to 6.8 [39]. The 
medium was dispensed into test tubes and sterilized in an autoclave. Seitz-filtered urea solution $(0.5 \mathrm{~mL} ; 20 \%, \mathrm{w} / \mathrm{v})$ was added aseptically to each test tube, and tubes were allowed to solidify with a long slope. Basal medium agar slant (without urea) was considered as a control. The agar slants were inoculated with loopful of fungal isolate PUPY-06 and incubated at $25^{\circ} \mathrm{C}$ for 4 days. The urea hydrolytic nature of the fungal culture was confirmed by formation of deep pink color on the agar slants.

\subsubsection{Diazonium blue B (DBB) color reaction}

DBB color reaction was observed on colonies of fungal isolate PUPY06 [40]. Fungal isolate was cultivated on YM agar plates containing $(\%, \mathrm{w} / \mathrm{v})$ : Yeast extract 0.3 ; malt extract 0.3 ; peptone 0.5 ; glucose 1 ; and agar 1.5. Agar plates were incubated at $25^{\circ} \mathrm{C}$ for 3 weeks. DBB reagent was prepared by dissolving $15 \mathrm{mg}$ of DBB salt in $15 \mathrm{~mL}$ of chilled tris (hydroxymethyl) aminomethane buffer $(0.25 \mathrm{M})$ with final $\mathrm{pH} 7.0$ and kept in an ice bath. Two drops of freshly prepared chilled DBB reagent were applied to the surface of the colony. The colonies were observed for development of dark violet red color in support of positive DBB color reaction.

\subsubsection{Growth tests}

\subsubsection{Growth temperature}

The growth of fungal isolate PUPY-06 at various temperatures was assessed in the glucose-nitrogen base medium as described by Wickerham [36]. The isolate was inoculated in glucose-nitrogen base medium and incubated at a range of temperature $(25,30,35,37,40$, and $42^{\circ} \mathrm{C}$ ) for 7 days. The growth of fungal isolate was observed at a particular temperature.

\subsubsection{Cycloheximide resistance}

The resistance of fungal isolate PUPY-06 to cycloheximide was investigated [41] using the liquid bacto-yeast nitrogen base medium with D-glucose as described by Wickerham [36]. Cycloheximide $(0.1 \%$ and $0.01 \%, \mathrm{w} / \mathrm{v})$ was added in two separate test tubes containing the above mentioned media. The media containing test tubes were inoculated with fungal isolate PUPY-06 and incubated at $25^{\circ} \mathrm{C}$ for 7 days. The positive or negative growth of fungal isolate was observed for each concentration of cycloheximide.

\subsubsection{Growth in media of high osmotic pressure}

The ability of isolate PUPY-06 to grow at high concentration of sugar (50\% and $60 \%$ glucose) and salt (10\% sodium chloride) was tested using glucose agar media $(50 \%)$ containing $(\%, \mathrm{w} / \mathrm{v})$ : Glucose 50 , yeast infusion 50; and agar 1.3; glucose agar media $(60 \%)$ containing $(\%, \mathrm{w} / \mathrm{v})$ : Glucose 60, yeast infusion 40; and agar 2.25; and sodium chloride glucose media containing $(\%, \mathrm{w} / \mathrm{v})$ : Sodium chloride 10 , glucose 5 ; and bacto-yeast nitrogen base 0.65 [36]. Agar slants were inoculated with loopful of fungal isolate PUPY-06 and incubated at $25^{\circ} \mathrm{C}$ for $48 \mathrm{~h}$. Growth of the isolate at high osmotic pressure was observed.

\subsubsection{Tolerance of $1 \%$ acetic acid}

The tolerance of fungal isolate PUPY-06 against 1\% acetic acid was examined using acetic acid agar medium containing (\%,w/v): Glucose 10; tryptone 1; yeast extract powder 1; and agar 2 [42]. Glacial acetic acid $(1 \%, v / v)$ was added to the sterile medium $\left(45-50^{\circ} \mathrm{C}\right)$, mixed well and poured into sterilized pertiplates. The test medium agar plates were inoculated with a loopful of cell suspension and incubated at $25^{\circ} \mathrm{C}$ for 7 days. The agar plates were examined for the development of colonies.

\subsubsection{Vitamin requirement}

The requirement of vitamins for growth was determined by inoculating fungal isolate PUPY-06 in a complete mineral medium devoid of all vitamins [36]. The test tube containing sterilized growth medium was inoculated with $100 \mu \mathrm{L}$ of inoculum and incubated at $25^{\circ} \mathrm{C}$ for 7 days, and distilled water was taken as control. The test tube was observed visually for the growth of culture in the absence of all the vitamins.

\subsubsection{Molecular characterization}

Genomic DNA was isolated from fungal isolate PUPY-06, using the genomic DNA isolation kit (GeNei, Bangalore, India). Using consensus primers of $\sim 1200 \mathrm{bp}, 18 \mathrm{~S} \mathrm{rRNA}$ (ITS1, 5.8S rRNA, ITS2, and 28S rRNA), gene fragments were amplified using high-fidelity PCR polymerase. The PCR product was sequenced using the forward and reverse primers. The PCR mix contained: Genomic DNA $20 \mathrm{ng}$, dNTP mix $(2.5 \mathrm{mM}$ each) $1.0 \mu \mathrm{L}$, forward primer $100 \mathrm{ng}$, reverse primer $100 \mathrm{ng}, \times 10$ assay buffer 5A 1X, XT-5 polymerase $3 \mathrm{U}$; and an appropriate quantity of glass distilled water to makeup the final volume $50 \mu \mathrm{L}$. The thermal cycle for both reactions included initial denaturation at $94^{\circ} \mathrm{C}$ for 5 min followed by 35 cycles of denaturation at $94^{\circ} \mathrm{C}$ for $30 \mathrm{~s}$, annealing at $56^{\circ} \mathrm{C}$ for $30 \mathrm{~s}$, and extension at $72^{\circ} \mathrm{C}$ for $1 \mathrm{~min} 30 \mathrm{~s}$ with a final extension at $72^{\circ} \mathrm{C}$ for $10 \mathrm{~min}$. The PCR products were loaded on $1.0 \%$ agarose gel along with StepUp ${ }^{\mathrm{TM}} 500 \mathrm{bp}$ DNA ladder. Sequence data were aligned against the reference nucleotide sequences of the genera retrieved from GenBank and analyzed using BLAST for finding the closest homologous microbe. The distance matrix was calculated based on nucleotide sequence homology using Kimura-2 parameter [43].

\subsection{Production of Pullulan with Time course as a Function}

The effect of fermentation time on pullulan production and biomass yield from fungal isolate PUPY-06 was investigated in shake-flask fermentations. The production medium $(100 \mathrm{~mL})$ in Erlenmeyer flasks (composition same as described in section 2.2.2) was inoculated with $5 \%(\mathrm{v} / \mathrm{v})$ for 2 days old culture and incubated at $25^{\circ} \mathrm{C}$ for 10 days, under agitation $(150 \mathrm{rpm})$. Samples were collected at $24 \mathrm{~h}$ intervals regularly and investigated for pullulan production and biomass yield.

\subsection{Pullulan Production with Agitation Mode of Cultivation as a Function}

A comparative study on pullulan production and biomass yield from fungal isolate PUPY-06 was done with agitation mode of cultivation as a function. In Erlenmeyer flasks $(250 \mathrm{~mL})$, production medium $(100 \mathrm{~mL}$; composition same as described in section 2.2.2) was inoculated with $5 \%(\mathrm{v} / \mathrm{v})$ of 2 days old culture. Shake-flask fermentations were carried out at $25^{\circ} \mathrm{C}$ for 7 days, under stationary and agitation $(150 \mathrm{rpm})$ mode of cultivation. After fermentation, the culture broth was analyzed for pullulan production and biomass yield.

\subsection{Analytical techniques}

\subsubsection{Pullulan estimation}

After shake-flask fermentations, culture broth was centrifuged (5000 rpm, $4{ }^{\circ} \mathrm{C}, 10 \mathrm{~min}$ ) and supernatant was precipitated with two volumes of chilled isopropyl alcohol. Mixture was left overnight for complete settlement of precipitates. The supernatant was decanted; precipitates were dissolved in distilled water and reprecipitated followed by washing with acetone. The precipitates were again dissolved in distilled water and dried at $70^{\circ} \mathrm{C}$, till a constant weight was obtained. Pullulan production was expressed as grams of pullulan produced per $100 \mathrm{~mL}$ supernatant of fermented broth.

\subsubsection{Estimation of biomass}

The fermentation broth was diluted 100 times, and its absorbance was taken at $600 \mathrm{~nm}$ using a spectrophotometer (DR/2500, HACH, USA) against cell-free broth as blank. 


\subsection{Characterization of crude pullulan}

\subsubsection{Fourier-transform infrared (FTIR) spectroscopy}

The crude pullulan was characterized by FTIR at Sophisticated Analytical Instrument Facility, RC, Panjab University, Chandigarh, India. The infrared spectrum was determined using potassium bromide technique on a spectrophotometer (Perkin-Elmer, Norwalk, CT). Pure pullulan (Sigma, USA) was used as a standard.

\subsubsection{Nuclear magnetic resonance (NMR) spectroscopy}

The structural confirmation of crude pullulan was carried out at Sophisticated Analytical Instrument Facility, RC, Panjab University, Chandigarh, India. Pulsed-field NMR experiments were performed on a Bruker AVANCE II 400 NMR spectrometer with a narrow bore magnet. A $5 \mathrm{~mm} 1 \mathrm{H} / \mathrm{BB}\left({ }^{109} \mathrm{Ag}-{ }^{31} \mathrm{P}\right)$ triple-axis gradient probe (ID500-5EB, Nalorac Cryogenic Corp.) was used for all diffusion measurements. The NMR probe in the $500 \mathrm{MHz}$ spectrophotometer was turned to $125.75 \mathrm{MHz}$ for ${ }^{13} \mathrm{C}$ frequency and for $500.128 \mathrm{MHz}$ for ${ }^{1} \mathrm{H}$ frequency. The samples were prepared by dissolving crude pullulan in deionized water $(\sim 0.6 \mathrm{~mL})$ to have approximately $1 \%$ solution for ${ }^{1} \mathrm{H}$ NMR and $25 \%$ solution for ${ }^{13} \mathrm{C}$ NMR. These dilutions were performed in glass and transferred to the $5 \mathrm{~mm}$ NMR tube for 2D analysis. All spectra were acquired at 298 K. 2, 2-dimethylsilapentane5 -sulfonic acid, $\delta=0.00$ was used as internal standard. Pure pullulan (Sigma, USA) was used as a standard for structural characterization.

\subsection{Statistical Analysis}

All the results are an average of three independent experiments. Data have been represented as \pm standard error mean.

\section{RESULTS AND DISCUSSIONS}

\subsection{Isolation and Screening of Fungal Isolates for Pullulan Production}

A total of 22 fungal strains were isolated by enrichment technique from fresh/decaying leaves of various plants on the basis of their colonial characteristics on agar plate cultures. Colonies of all the isolated fungal strains produced a colored pigment which varied from beige to orange. The isolated strains were melanin-free as none of the isolate produced any dark- or black-colored pigment (melanin). The appearance of isolates colonies was in line with the study of Pollock et al. [34]. Colonial surface texture of each isolated fungal strain was smooth and shiny. All the fungal isolates were screened for pullulan production [Table 1]. Among them, the fungal isolate PUPY-06 from leaves of $F$. lacor was found most efficient pullulan producer $(2.12 \%, \mathrm{w} / \mathrm{v})$. The nature and magnitude of pullulan production was similar to that from A. pullulans [44] and Eurotium chevalieri [45]. Based on these findings, the fungal isolate PUPY-06 was selected for further investigations.

\subsection{Identification of Efficient Pullulan-producing Fungal Isolate PUPY-06}

\subsubsection{Morphological studies}

The most efficient pullulan-producing fungal isolate PUPY-06 was investigated for macromorphological and cellular characteristics. The fungal isolate PUPY-06 showed good growth on PDA plates after 7 days of cultivation at $25^{\circ} \mathrm{C}$. The colony color of fungal isolate varied from orange to beige, without any dark-colored pigmentation even after 30 days of cultivation. The dark pigment-producing strains have been reported to fit in chlamydospores and the pink-pigmented cultures from hyaline blastospores [16]. The colony color of fungal isolate on freshly inoculated PDA plates was orange up to 20 days of cultivation at $25^{\circ} \mathrm{C}$
Table 1: Pullulan production from fungal isolates collected from leaves of different plants.

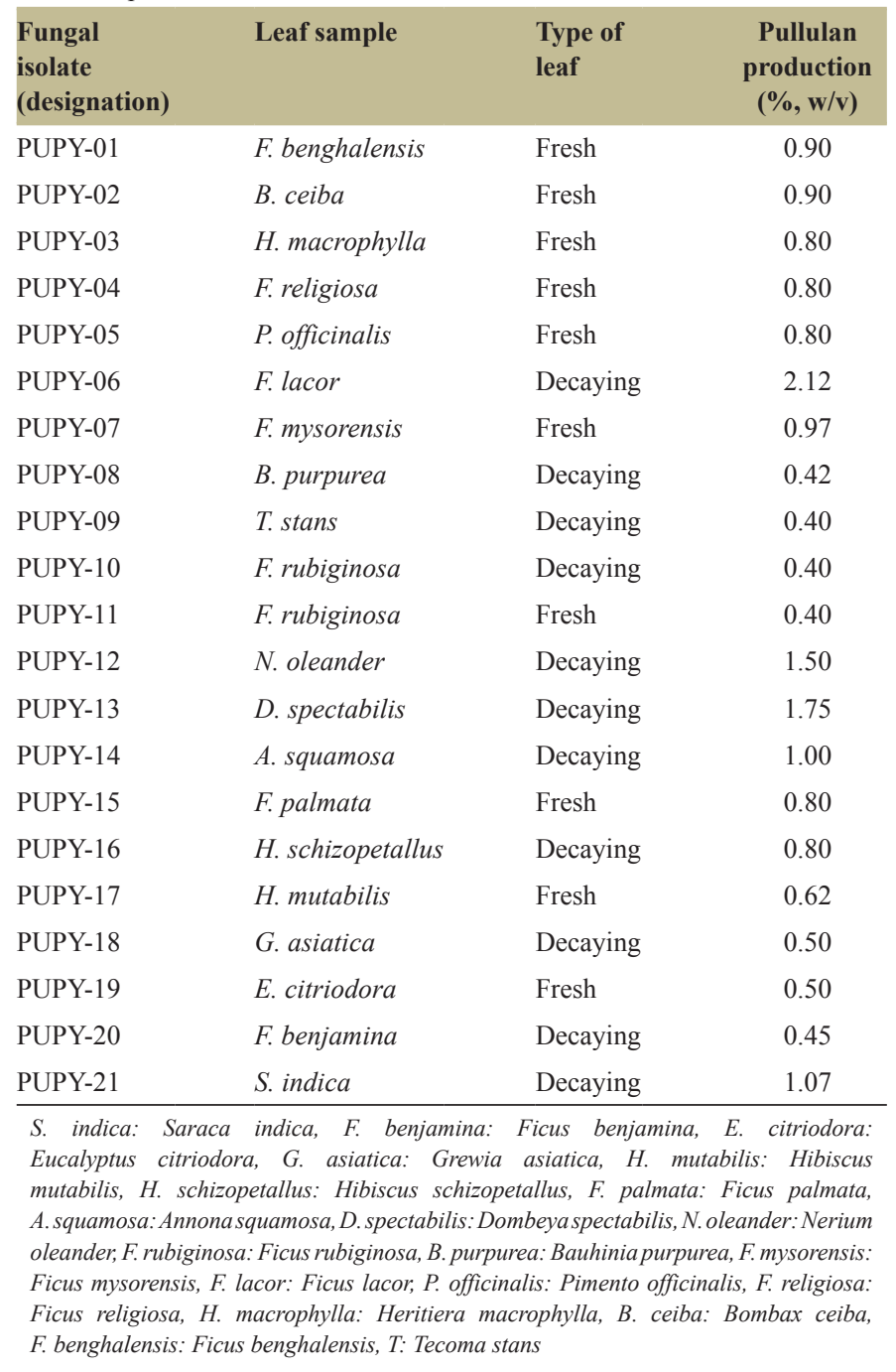

and turned to beige color afterward. The colonies of fungal isolate were smooth, shiny, and mucoid giving it the yeast-like characteristics. The colonies were round, butyrous, and had entire colony margin. The colony characteristics of fungal isolate [Table 2] go in line with the study of Fell and Tallman [35]. The results are in accordance with the taxonomic key of Kurtzman and Fell [46]. Further, the microscopic study of fungal isolate cells revealed its minute and unique features for its identification. The oval or cylindrically shaped cells of fungal isolate multiplied through budding. The cells showed sexual reproduction producing varied shaped basidia. The teliospores appeared in clusters of 2-4 after 4 days of cultivation at $25^{\circ} \mathrm{C}$. Teliospores were intercalary and very less terminal on the mycelium. The presence of septate hyphae and pseudohyphae was observed after 7 days. The branched septate filaments, blastospores, and chlamydospores were present at the cellular level [Figure 1]. These observations are consistent with the description given by Fell and Tallman [35] and portray the strain to Rhodosporidium sp. The characteristics investigated on the basis of yeast taxonomy [46] also predicted the fungal isolate PUPY-06 as Rhodosporidium $\mathrm{sp.}$

\subsubsection{Physiological and biochemical characterization}

The physiological and biochemical properties of fungal isolate PUPY-06 were correlated with the taxonomic study of Kurtzman and 
Fell [46]. The fungal isolate has shown positive utilization of galactitol, D-ribose, L-arabinose, L-rhamnose, ribitol, and D-mannitol [Table 3]. Fungal isolate has also shown an affirmative assimilation of 30 carbon sources [Table 3]. Of 13 different nitrogen compounds, fungal isolate assimilated ammonium sulfate, ethylamine, nitrate, nitrite, potassium nitrate, and sodium nitrate [Table 3]. The fungal isolate showed the negative response for the formation of starch-like extracellular polysaccharides. Similarly, results for acetic acid production by fungal isolate were off-putting. There was no acetic acid production by fungal isolate. On the other hand, fungal isolate showed positive results for urea hydrolysis. DBB color reaction indicated that fungal isolate PUPY-06 may belong to basidiomycetous yeasts as the colonies of isolate produced dark violet red color in the medium. All these results [Table 3] were compared with the published data $[35,47]$ and found to be in accordance with them, indicating the isolate to be $R$. paludigenum.

\subsubsection{Growth tests}

Various studies on pullulan production from $A$. pullulans suggest that optimal temperature for pullulan production depends on the strain variations $[48,49]$. The fungal isolate PUPY-06 was able to fully grow at $25^{\circ} \mathrm{C}$ and $30^{\circ} \mathrm{C}$ only. Among other growth factors, fungal isolate was unable to tolerate $1 \%$ of acetic acid. In contrary, fungal isolate was well grown in the presence of cycloheximide $(0.1 \%$ and $0.01 \%)$. The growth of fungal isolate was observed dreadfully fine at high osmotic pressure, both in case of high concentration of glucose $(50 \%$ and $60 \%)$ and sodium chloride (10\%). The vitamin-free medium used for growth of fungal isolate showed a positive response. The fungal isolate can grow well even in the medium devoid of all the vitamins. The results of all the growth tests on fungal isolate [Table 3] are in agreement with the findings on $R$. paludigenum by Fell and Tallman [35]. Similar results have been reported for $R$. paludigenum DMKU3-LPK4 by Yimyoo et al. [47].

\subsubsection{Molecular characterization}

Morphological and biochemical characteristics identified the fungal isolate PUPY-06 up to generic level. Identification of species-specific characteristics and confirmation of generic level for isolate were obtained from molecular characterization and phylogenetic analysis. A sequence of 1185 base pair was obtained by amplification of sequence from $18 \mathrm{~S}$ rRNA gene sequencing. The comparative analysis and homology (nBLAST) of 18S rRNA gene sequence of fungal isolate showed $99 \%$ similarity with a sequence of $R$. paludigenum (KF411500). The fungal isolate PUPY-06 is a teleomorphic fungus of division Basidiomycota, class Microbotryomycetes [31], and family Sporidiobolaceae [33]. The closest homolog was found to be Rhodotorula glutinis (FJ345357). Distance matrix based on nucleotide sequence homology using Kimura-2 parameter indicated the nucleotide similarity (above diagonal) and distance (below diagonal) between isolate PUPY-06 and 10 other closest homologous microbes. The 18S rRNA gene sequence analysis and the unrooted phylogenetic tree [Figure 2] analysis verified fungal isolate PUPY06 as $R$. paludigenum. 18S rRNA sequence of isolate PUPY-06 was submitted to the GenBank database, and it was assigned accession number KT807881.

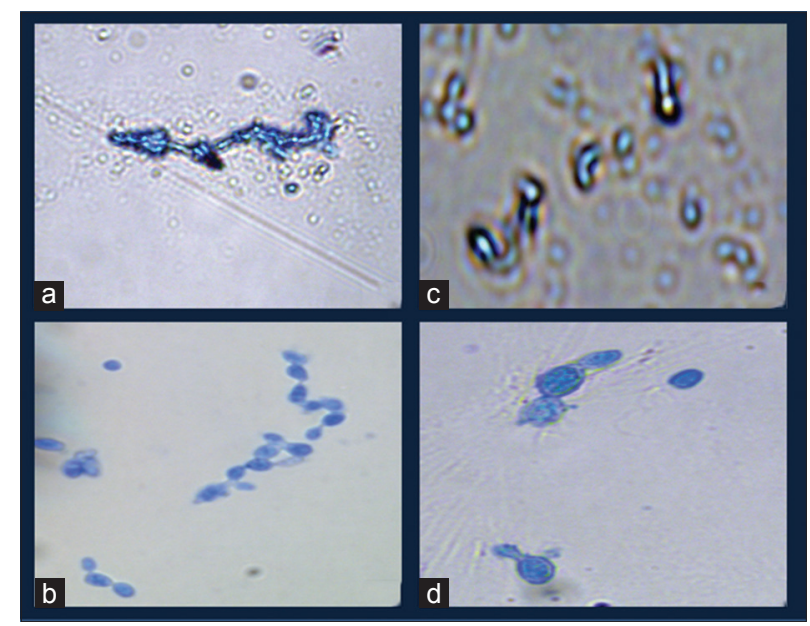

Figure 1: Microscopic view of Rhodosporidium paludigenum PUPY-06: (a) Pseudohyphae, (b) septate hyphae, (c) transverse septation of basidia, (d) oval-shaped yeast cells showing bipolar and sympodial budding.

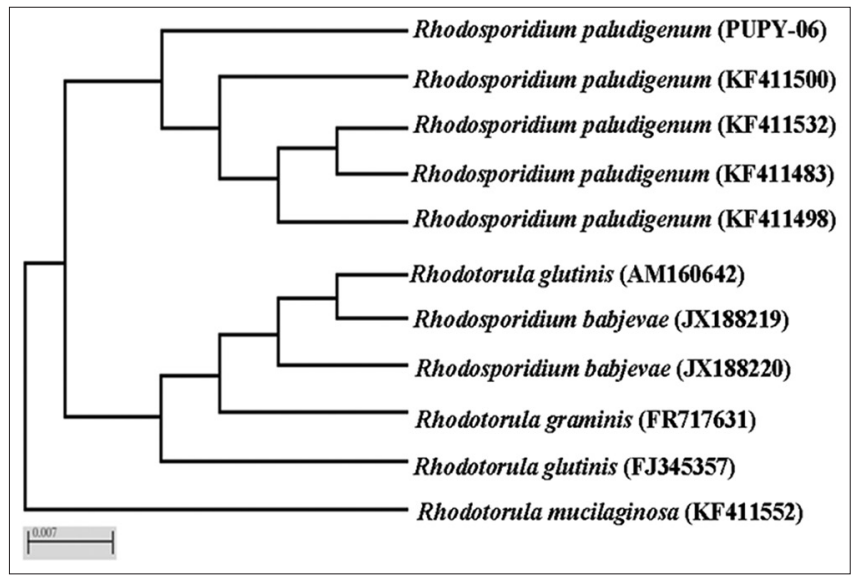

Figure 2: Phylogenetic tree showing relationship of the 18S rRNA sequence of Rhodosporidium paludigenum PUPY-06 with its close homologs.

Table 2: Morphological characteristics of R. paludigenum PUPY-06 at macroscopic and microscopic level.

\begin{tabular}{llll} 
& Macromorphology & & Micromorphology \\
Characteristics & Result & Characteristics & Result \\
Colony color & Beige to orange & Budding & Bipolar and sympodial \\
Colony appearance & Smooth & Cell shape & Oval and cylindrical \\
Colony margin & Entire & Sexual reproduction & Basidiomycetous \\
Colony texture & Mucoid and butyrous & Basidia shape & Calvate and cylindrical \\
& & Basidia septation & Transversely septate \\
& & Basidia catenate-solitary & Solitary \\
& & Teliospores & Round to oval \\
& & Filaments & Septate hyphae and pseudohyphae \\
\hline
\end{tabular}


Table 3: Biochemical and physiological characteristics of R. paludigenum PUPY-06.

\begin{tabular}{|c|c|c|c|c|c|}
\hline \multicolumn{6}{|c|}{ Fermentation } \\
\hline D-Glucose & - & D-Ribose & + & L-Rhamnose & + \\
\hline D-Galactose & - & Cellobiose & - & Erythritol & - \\
\hline Maltose & - & Raffinose & - & Ribitol & + \\
\hline$\alpha$-Methyl-D-Glucoside & - & Melibiose & - & D-Mannitol & + \\
\hline \multicolumn{6}{|c|}{ Assimilation of carbon compounds } \\
\hline D-Glucose & + & Arbutin & + & Inositol & - \\
\hline D-Galactose & + & Melibiose & - & D-Glucono-1,5-lactone & + \\
\hline L-Sorbose & + & Lactose & - & 2-Keto-D-Gluconate & + \\
\hline L-Arabinose & + & Starch & - & DL-Lactate & - \\
\hline D-Arabinose & + & Glycerol & + & Succinate & + \\
\hline L-Rhamnose & - & Erythritol & - & Citrate & + \\
\hline Sucrose & + & Ribitol & + & Propane-1,2-diol & + \\
\hline Maltose & + & Xylitol & + & Butane-2,3-diol & - \\
\hline Trehalose & + & L-Arabinitol & + & Quinic acid & + \\
\hline$\alpha$-Methyl-D-Glucoside & - & D-Glucitol & + & D-Glucarate & + \\
\hline Cellobiose & + & D-Mannitol & + & D-Galactonate & - \\
\hline Salicin & + & Galactitol & + & 5-Keto-D-Gluconate & - \\
\hline Glucitol & + & Ethanol & - & Galacturonic acid & - \\
\hline \multicolumn{6}{|c|}{ Assimilation of nitrogen compounds } \\
\hline Cadaverine & - & D-Tryptophan & - & & \\
\hline \multicolumn{6}{|c|}{ Other characteristics } \\
\hline Starch formation & - & Urea hydrolysis & + & DBB reaction & + \\
\hline Acetic acid production & - & & & & \\
\hline \multicolumn{6}{|c|}{ Growth tests } \\
\hline $25^{\circ} \mathrm{C}$ & + & Cycloheximide $0.01 \%$ & + & Glucose $50 \%$ & + \\
\hline $30^{\circ} \mathrm{C}$ & + & Cycloheximide $0.1 \%$ & + & Glucose $60 \%$ & + \\
\hline $35^{\circ} \mathrm{C}$ & - & Sodium chloride $10 \%$ & + & & \\
\hline $37^{\circ} \mathrm{C}$ & - & Acetic acid $1 \%$ & - & & \\
\hline $40^{\circ} \mathrm{C}$ & - & Vitamin free medium & + & & \\
\hline $42^{\circ} \mathrm{C}$ & - & & & & \\
\hline
\end{tabular}

-: Negative, + : Positive

\subsection{Production of Pullulan with Time course as a Function}

Pullulan production with time course as a function was investigated in shake-flask fermentations for 10 days at $25^{\circ} \mathrm{C}$. Maximum pullulan production $(2.12 \%, \mathrm{w} / \mathrm{v})$ was observed after 7 days of cultivation [Figure 3]. The exponential increase in pullulan concentration with increase in biomass yield suggested that pullulan production is growth associated up to 7 days of cultivation. Thereafter, a slight decrease was observed in both the functions. The reduction in pullulan production could be attributed to the high viscosity of broth, resulting in a limited availability of nutrients and oxygen to the culture during fermentation. Our results corroborate the findings on pullulan production from A. pullulans $[44,50]$ and $R$. bacarum [4]. 


\subsection{Pullulan Production with Agitation Mode of Cultivation as a Function}

The influence of agitation mode of cultivation on pullulan production was observed in shake-flask fermentations. Pullulan production from

Table 4: Comparative infrared spectroscopy data of pure pullulan (Sigma, USA) and crude pullulan from R. paludigenum PUPY-06

\begin{tabular}{lcc} 
Assignment & \multicolumn{2}{c}{ Wave number $\left.\mathbf{( c m}^{-1}\right)$} \\
\cline { 2 - 3 } H structure & Sigma & Crude pullulan \\
C-H structure & 3433.3 & 3423.2 \\
O-C-O structure & 2925.3 & 2934.3 \\
C-O-H bend & 1645.4 & 1654.3 \\
C-O-C structure & 1423.4 & 1419.3 \\
C-O structure & 1158.4 & 1256.3 \\
$\alpha$-configuration & 1019.4 & 1076.2 \\
\hline
\end{tabular}

R. paludigenum: Rhodosporidium paludigenum

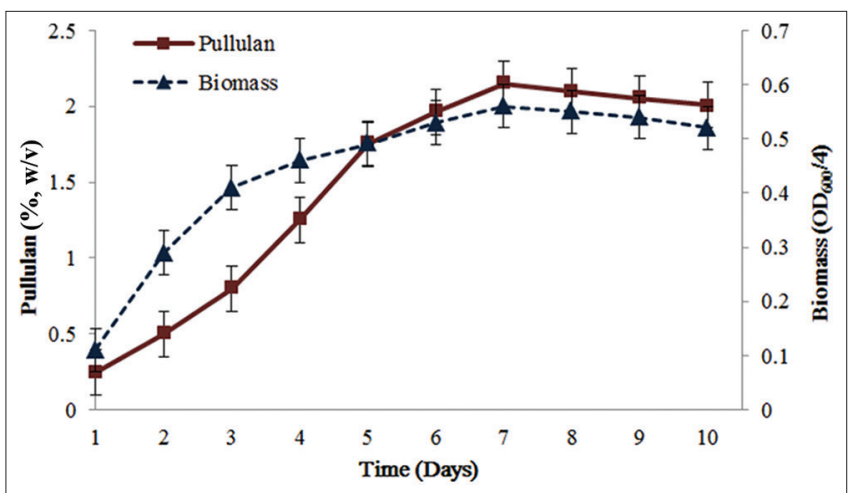

Figure 3: Pullulan production from Rhodosporidium paludigenum PUPY-06 with time course as a function. fungal isolate PUPY-06 was higher $(2.10 \%, w / v)$ under agitation $(150 \mathrm{rpm})$ mode of cultivation than under stationary $(0.68 \%, \mathrm{w} / \mathrm{v})$ condition, after 7 days of incubation at $25^{\circ} \mathrm{C}$ [Figure 4]. The agitation mode of cultivation has shown an insightful influence on pullulan production as it facilitates the provision of oxygen to the fungus. Agitation maintains uniformity of microbial cells in broth during fermentation and also increases the nutrient availability which leads to higher pullulan production. Agitation also maintains both heat and mass transfer factors during fermentation. Agitation mode of cultivation has been reported best for pullulan production from A. pullulans [51-54] and $R$. bacarum [4] in shake-flask fermentations.

\subsection{Characterization of Crude Pullulan}

\subsubsection{FTIR spectroscopy of crude pullulan}

FTIR spectra of crude pullulan from PUPY-06 illustrated almost the similar peaks as from standard pullulan [Table 4]. The presence of $\alpha$-configuration within the pullulan can be indicated by a peak at around $\lambda=850 \mathrm{~cm}^{-1}$ [44]. The significant peak at $\lambda=820 \mathrm{~cm}^{-1}$ indicates $\alpha$-configuration in structure of crude pullulan [Figure 5]. Similar results have also been reported with a peak at $\lambda=859 \mathrm{~cm}^{-1}$ corresponding to $\alpha$-configuration $[55,56]$. The wave numbers $3433.3 \mathrm{~cm}^{-1}$ and $2925.3 \mathrm{~cm}^{-1}$ signify existence of $\mathrm{H}$-bond and $\mathrm{C}-\mathrm{H}$ stretching, respectively, and similar results were found for crude pullulan with absorbance at $3423.2 \mathrm{~cm}^{-1}$ and $2934.3 \mathrm{~cm}^{-1}$. The band at about $1158.4 \mathrm{~cm}^{-1}$ was assigned to vibrations of C-O-C bond and glycosidic bridge [57], and the results of crude pullulan comply approximately the same peaks at $\lambda=1256.3 \mathrm{~cm}^{-1}$. The existence of O-C-O for standard pullulan can be depicted by peaks at $\lambda=1645.4$ $\mathrm{cm}^{-1}$, and comparable peaks were observed for crude pullulan at $\lambda=1654.3 \mathrm{~cm}^{-1}$. The structure of crude pullulan was confirmed further due to the presence of $\mathrm{C}-\mathrm{O}-\mathrm{H}$ bond with a significant peak at $\lambda=1419.3 \mathrm{~cm}^{-1}$. The broad peak at around $\lambda=1019.4 \mathrm{~cm}^{-1}$ should be most likely ascribed to the vibration of the $\mathrm{C}-\mathrm{O}$ bond at the $\mathrm{C}-4$ position of a glucose residue [58], and crude pullulan spectra showed a comparable peak at $\lambda=1076.2 \mathrm{~cm}^{-1}$.

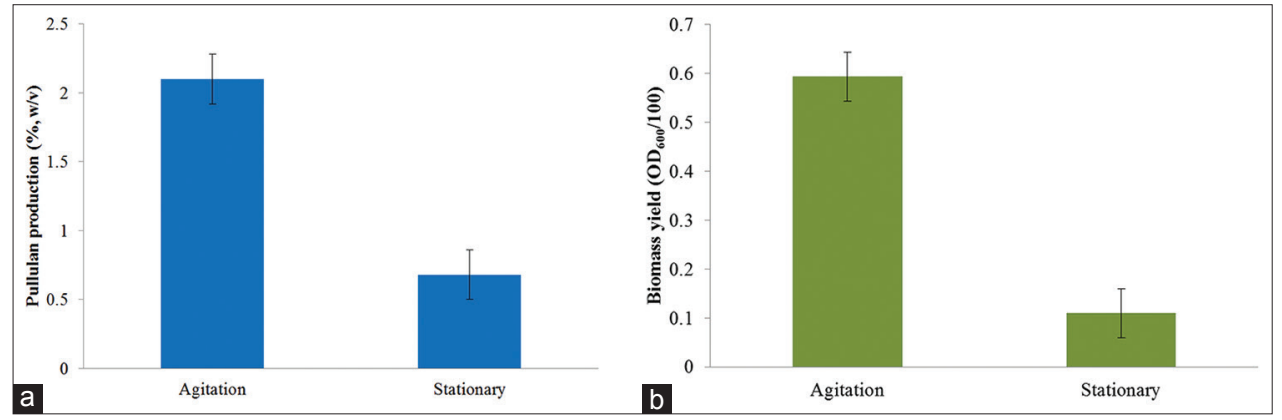

Figure 4: Rhodosporidium paludigenum PUPY-06 cultivation with agitation mode as a function for: (a) Pullulan production and (b) biomass yield.

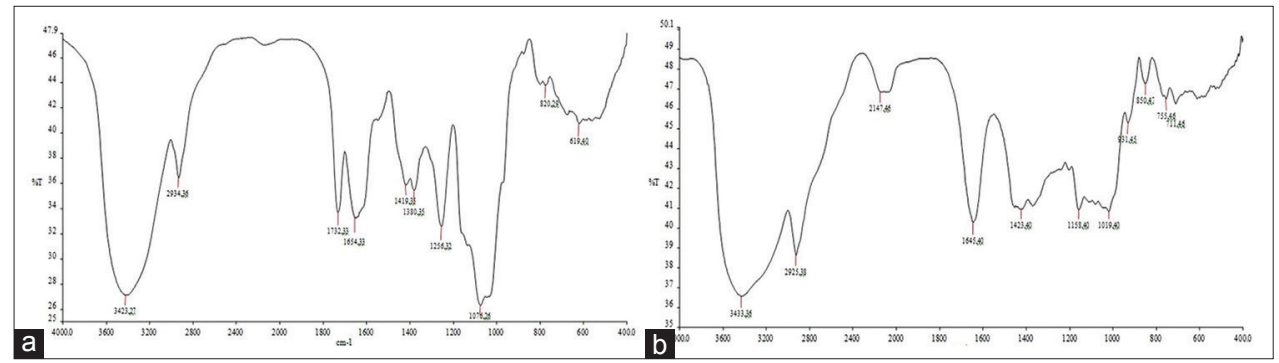

Figure 5: Fourier-transform infrared spectroscopy of pullulan: (a) Crude pullulan from R. paludigenum PUPY-06, (b) pure pullulan (Sigma, USA). \%T: Percentage transmittance. 


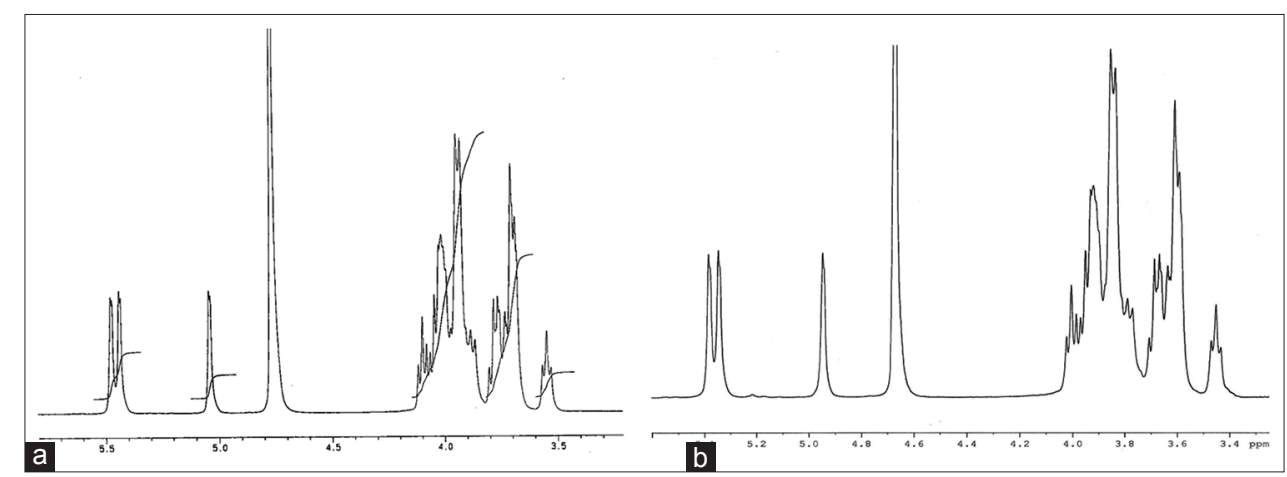

Figure 6: Proton NMR spectra of: (a) Pure pullulan (Sigma, USA), (b) crude pullulan from Rhodosporidium paludigenum PUPY-06.

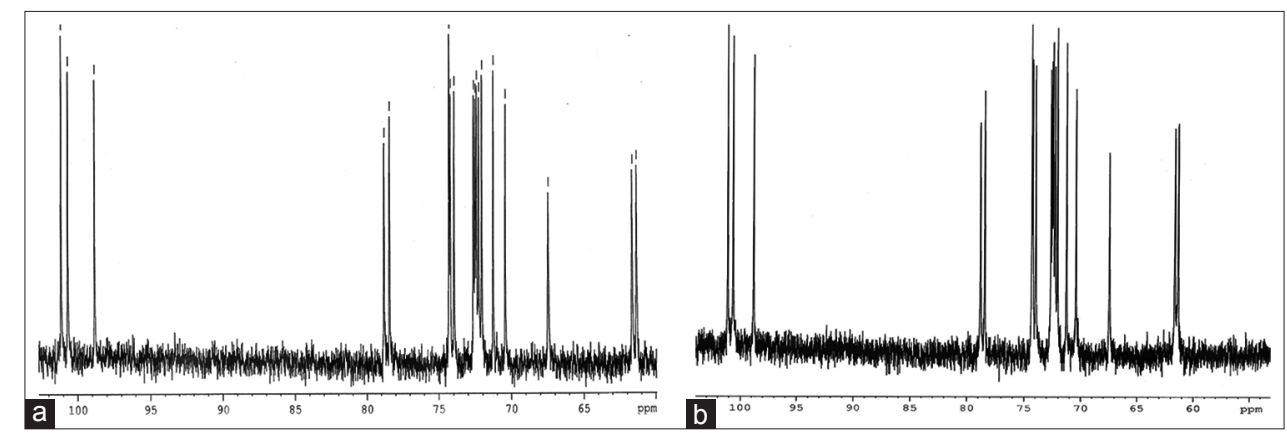

Figure 7: Carbon-13 NMR spectrum (proton decoupled) of: (a) Pure pullulan (Sigma, USA), (b) crude pullulan from Rhodosporidium paludigenum PUPY-06.

\subsubsection{NMR spectroscopy of crude pullulan}

NMR spectroscopy of crude pullulan from $R$. paludigenum PUPY-06 further confirmed the presence of $\alpha-(1 \rightarrow 4)$ and $\alpha-(1 \rightarrow 6)$ linkages (ratio 2:1) in its structure [Figures 6 and 7]. The ${ }^{1} \mathrm{H}$ and ${ }^{13} \mathrm{C}$ spectra for PUPY-06 pullulan were almost similar to the standard pullulan (Sigma, USA). The spectra of both samples showed that $\alpha-(1 \rightarrow 6)$ linkage is present between every third glucose ring. Proton spectrum gave proportion of $\alpha-(1 \rightarrow 6)$ linkages of around 0.34 and 0.32 from ${ }^{13} \mathrm{C}$ spectrum which signifies the presence of only maltotriose units in a homogenous manner for PUPY-06 pullulan and standard pullulan (Sigma, USA). NMR spectroscopy has been reported to investigate the primary structure of pullulan $[59,60]$. The ${ }^{1} \mathrm{H}$ NMR spectra gave the detailed information about the occurrence of different linkages in the structure on the basis of chemical shifts [Figure $6 \mathrm{a}$ and b]. The signals at $5.02 \mathrm{ppm}$ for standard pullulan (Sigma, USA) and $5.04 \mathrm{ppm}$ for PUPY-06 pullulan signified the presence of anomeric proton at $\alpha-(1 \rightarrow 6)$ linkage due to their chemical shifts. The signals at $5.46 \mathrm{ppm}$ and $5.42 \mathrm{ppm}$ for standard pullulan (Sigma, USA) are well known for the presence of $\alpha-(1 \rightarrow 4)$ linkage based on their chemical shifts, and similar signals were found for PUPY-06 pullulan at $5.44 \mathrm{ppm}$ and $5.48 \mathrm{ppm}$. Along with, weak signals at $5.42 \mathrm{ppm}$ and $4.72 \mathrm{ppm}$ indicated the presence of $\alpha$ and $\beta$ anomers of the terminal glucose residue in fewer amounts. The spectra of ${ }^{13} \mathrm{C}$ NMR further confirmed the homogeneity of PUPY-06 pullulan [Figure 7a and b]. The signals at $98.76 \mathrm{ppm}$ for standard pullulan (Sigma, USA) and $99.00 \mathrm{ppm}$ for PUPY-06 pullulan signified the occurrence of anomeric $\alpha-(1 \rightarrow 6)$ carbon. The shifts of anomeric $(1 \rightarrow 4)$ linked carbon depending on the linkage of preceding residue were $100.64 \mathrm{ppm}$ or $101.10 \mathrm{ppm}$ for standard pullulan (Sigma, USA) and $100.60 \mathrm{ppm}$ or $101.10 \mathrm{ppm}$ for PUPY-06 pullulan. The confirmation of structural characteristics of pullulan by ${ }^{13} \mathrm{C}$ NMR spectroscopy has been found similar with Youssef et al. [61]. Our results corroborate the findings on pullulan production from $A$. pullulans [62].

\section{CONCLUSIONS}

Among the various fungal isolates screened for pullulan production, fungal isolate PUPY-06 has been proved as the best pullulan producer. The structural elucidation of crude pullulan by FTIR and NMR confirmed its characteristics as pullulan. The agitation mode of cultivation has been proved best for the production of pullulan in shake-flask fermentations. To the best of our knowledge, no strain of $R$. paludigenum has been reported for pullulan production so far. The present study will provide very useful guidelines for further investigations on pullulan production from $R$. paludigenum for future research.

\section{REFERENCES}

1. Fraser CG, Jennings HJ. A glucan from Tremella mesenterica NRRL-Y6158. Can J Chem 1971;49:1804-7.

2. Waksman N, Lederkremer RM, Cerezo AS. The structure of an $\alpha$-Dglucan from Cyttaria harioti fischer. Carbohydr Res 1977;59:505-15.

3. Oliva EM, Cirelli AF, Lederkremer RM. Characterization of a pullulan in Cyttaria darwinii. Carbohydr Res 1986;158:262-7.

4. Chi Z, Zhao S. Optimization of medium and new cultivation conditions for pullulan production by a new pullulan-producing yeast strain. Enzyme Microb Technol 2003;33:206-11.

5. Corsaro MM, Castro C, Evidente A, Lanzetta R, Molinaro A, Parrilli M, et al. Phytotoxic extracellular polysaccharide fractions from Cryphonectria parasitica (Murr) Barr strains. Carbohydr Polym 1998;37:167-72.

6. Reis RA, Tischer CA, Gorin PA, Iacomini M. A new pullulan and a branched $(1 \rightarrow 3)-, \quad(1 \rightarrow 6)$-linked beta-glucan from the lichenised ascomycete Teloschistes flavicans. FEMS Microbiol Lett 2002;210:1-5.

7. Delben F, Forabosco A, Guerrini M, Liut G, Torri G. Pullulans produced by strains of Cryphonectria parasitica-II. Nuclear magnetic 
resonance evidence. Carbohydr Polym 2006;63:545-54.

8. Forabosco A, Bruno G, Sparapano L, Liut G, Marino D, Delben F. Pullulans produced by strains of Cryphonectria parasitica-I. Production and characterization of the exopolysaccharides. Carbohydr Polym 2006;63:535-44.

9. Singh RS, Saini GK, Kennedy JF. Pullulan: Microbial sources, production and applications. Carbohydr Polym 2008;73:515-31.

10. Singh RS, Saini GK. Pullulan-hyperproducing color variant strain of Aureobasidium pullulans FB-1 newly isolated from phylloplane of Ficus sp. Bioresour Technol 2008;99:3896-9.

11. Sugimoto K. Pullulan production and applications. J Ferment Assoc Jpn 1978;36:98-108.

12. Tsujisaka Y, Mitsuhashi M. Pullulan. In: Whistler RL, BeMiller JN, editors. Industrial Gums, Polysaccharides and their Derivatives. San Diego, California: Academic Press; 1993. p. 447-60.

13. Shingel KI. Current knowledge on biosynthesis, biological activity, and chemical modification of the exopolysaccharide, pullulan. Carbohydr Res 2004;339:447-60.

14. Singh RS, Saini GK. Pullulan as therapeutic tool in biomedical applications. In: Singh RS, Pandey A, Larroche C, editors. Advances in Industrial Biotechnology. India: IK International Publishing House Pvt. Ltd.; 2014. p. 263-91.

15. Singh RS, Saini GK. Biosynthesis of pullulan and its applications in food and pharmaceutical industry. In: Satyanarayana T, Johri BN, Prakash A, editors. Microorganisms in Sustainable Agriculture and Biotechnology. Part 2. New Delhi: Springer Science + Business Media B.V; 2012. p. 509-53.

16. Leathers TD. Biotechnological production and applications of pullulan. Appl Microbiol Biotechnol. 2003;62:468-73.

17. Singh RS, Kaur N. Microbial biopolymers for edible film and coating applications. In: Nawani NN, Khetmalas M, Razdan PN, Pandey A, editors. Advances in Biotechnology. India: IK International Publishing; 2015. p. 187-216.

18. Singh RS, Saini GK, Kennedy JF. Covalent immobilization and thermodynamic characterization of pullulanase for the hydrolysis of pullulan in batch system. Carbohydr Polym 2010;81:252-9.

19. Singh RS, Saini GK, Kennedy JF. Maltotriose syrup preparation from pullulan using pullulanase. Carbohydr Polym 2010;80:401-7.

20. Singh RS, Saini GK, Kennedy JF. Continuous hydrolysis of pullulan using covalently immobilized pullulanase in a packed bed reactor. Carbohydr Polym 2011;83:672-5.

21. Singh RS, Kaur N, Kennedy JF. Pullulan and pullulan derivatives as promising biomolecules for drug and gene targeting. Carbohydr Polym 2015;123:190-207.

22. Singh RS, Kaur N, Rana V, Kennedy JF. Pullulan: A novel molecule for biomedical applications. Carbohydr Polym 2017;171:102-21.

23. Singh RS, Kaur N, Rana V, Kennedy JF. Recent insights on applications of pullulan in tissue engineering. Carbohydr Polym 2016;153:455-62.

24. Kageyama S, Wada H, Muro K, Niwa Y, Ueda S, Miyata H, et al. Dose-dependent effects of NY-ESO-1 protein vaccine complexed with cholesteryl pullulan (CHP-NY-ESO-1) on immune responses and survival benefits of esophageal cancer patients. J Transl Med 2013;11:246.

25. Kong IG, Sato A, Yuki Y, Nochi T, Takahashi H, Sawada S, et al. Nanogel-based PspA intranasal vaccine prevents invasive disease and nasal colonization by Streptococcus pneumonia. Infect Immun 2013;81:1625-34.

26. Kong SH, Noh YW, Suh YS, Park HS, Lee HJ, Kang KW, et al. Evaluation of the novel near-infrared fluorescence tracers pullulan polymer nanogel and indocyanine green $/ \gamma$-glutamic acid complex for sentinel lymph node navigation surgery in large animal models. Gastric Cancer 2015;18:55-64.

27. Kulicke WM, Heinze T. Improvements in polysaccharides for use as blood plasma expanders. Macromol Symp 2006;231:47-59.

28. Sawada SI, Sasaki Y, Nomura Y, Akiyoshi K. Cyclodextrinresponsive nanogel as an artificial chaperone for horseradish peroxidase. Colloids Polym Sci 2011;289:685-91.

29. Chatap VK, Maurya AR, Deshmukh PK, Zawar LR. Formulation and evaluation of nisoldipne sublingual tablets using pullulan and chitosan for rapid oromucosal absorption. Adv Pharmacol Pharm 2013;1:18-25.

30. Bauer R, Begerow D, Sampaio JP, Weiss M, Oberwinkler F. The simple-septate basidiomycetes: A synopsis. Mycol Prog 2006;5:41-66.

31. Toome M, Roberson RW, Aime MC. Meredithblackwellia eburnea gen. et sp. nov., kriegeriaceae fam. nov. and kriegeriales ord. nov.-toward resolving higher-level classification in microbotryomycetes. Mycologia 2013;105:486-95.

32. Kirk PM, Cannon PF, Minter DW, Stalpers JA. Dictionary of the Fungi. $10^{\text {th }}$ ed. Wallingford, UK: CAB International; 2008.

33. Moore RT. Taxonomic proposals for the classification of marine yeasts and other yeast-like fungi including the smuts. Bot Mar 1980;23:361-73.

34. Pollock TJ, Thorne L, Armentrout RW. Isolation of new Aureobasidium strains that produce high-molecular-weight pullulan with reduced pigmentation. Appl Environ Microbiol 1992;58:877-83.

35. Fell JW, Tallman AS. Rhodosporidium paludigenum sp. nov., a basidiomycetous yeast from intertidal waters of South Florida. Int J Syst Bacteriol 1980;30:658-9.

36. Wickerham LJ. Taxonomy of yeasts. Tech Bull U S Dep Agric 1951;1029:1-55.

37. Custers MT. Onderzoekingen Over het Gistgeslacht Brettanomyces. PhD Thesis. The Netherlands: Technische Hoogeschool te Delft; 1940.

38. Seeliger HP. Use of a urease test for the screening and identification of cryptococci. J Bacteriol 1956;72:127-31.

39. Christensen WB. Urea decomposition as a means of differentiating proteus and paracolon cultures from each other and from Salmonella and Shigella types. J Bacteriol 1946;52:461-6.

40. Van Der Walt JP, Hopsu-Havu VK. A colour reaction for the differentiation of Ascomycetous and hemibasidiomycetous yeasts. Antonie Van Leeuwenhoek 1976;42:157-63.

41. Whiffen AJ. The production, assay, and antibiotic activity of actidione, an antiobiotic from Streptomyces griseus. J Bacteriol 1948;56:283-91.

42. Yarrow D. Zygosaccharomyces barker. In: Rij NJ, editor. The Yeasts - A Taxonomic Study. Amsterdam: Elsevier; 1984. p. 449-65.

43. Kimura M. A simple method for estimating evolutionary rates of base substitutions through comparative studies of nucleotide sequences. J Mol Evol 1980;16:111-20.

44. Singh RS, Saini GK. Production, purification and characterization of pullulan from a novel strain of Aureobasidium pullulans FB-1. J Biotechnol 2008;136:S506-7.

45. Gaur R, Singh R, Tiwari S, Yadav SK, Daramwal NS. Optimization of physico-chemical and nutritional parameters for a novel pullulan-producing fungus, Eurotium chevalieri. J Appl Microbiol 2010;109:1035-43.

46. Kurtzman CP, Fell JW. The yeasts. A Taxonomic Study. $4^{\text {th }}$ ed. Amsterdam: Elsevier; 1998.

47. Yimyoo T, Yongmanitchai W, Limtong S. Carotenoid production by Rhodosporidium paludigenum DMKU3-LPK4 using glycerol as the carbon source. Kasetsart J (Natural Science) 2011;45:90-100.

48. Lee JH, Kim JH, Zhu IH, Zhan XB, Lee JW, Shin DH, et al. Optimization of conditions for the production of pullulan and high molecular weight pullulan by Aureobasidium pullulans. Biotechnol Lett 2001;23:817-20.

49. Lazaridou A, Roukas T, Biliaderies CG, Vaikousi H. Characterization 
of pullulan produced from beet molasses by Aureobasidium pullulans in a stirred tank reactor under varying agitation. Enzyme Microb Technol 2002;31:122-32.

50. Singh RS, Singh H, Saini GK. Response surface optimization of the critical medium components for pullulan production by Aureobasidium pullulans FB-1. Appl Biochem Biotechnol 2009;152:42-53.

51. Gibbs PA, Seviour RJ. Does the agitation rate and/or oxygen saturation influence exopolysaccharide production by Aureobasidium pullulans in batch culture? Appl Microbiol Biotechnol 1996;46:503-10.

52. Punnapayak H, Sudhadham M, Prasongsuk S, Pichayangkura S. Characterization of Aureobasidium pullulans isolated from airborne spores in Thailand. J Ind Microbiol Biotechnol 2003;30:89-94.

53. Prasongsuk S, Berhow MA, Dunlap CA, Weisleder D, Leathers TD, Eveleigh DE, et al. Pullulan production by tropical isolates of Aureobasidium pullulans. J Ind Microbiol Biotechnol 2007;34:55-61.

54. Prasongsuk S, Sullivan RF, Kuhirun M, Eveleigh DE, Punnapayak H. Thailand habitats as sources of pullulan-producing strains of Aureobasidium pullulans. World J Microbiol Biotechnol 2005;21:393-8.

55. Madi NS, Harvey LM, Mehlert A, McNeil B. Synthesis of two distinct exopolysaccharide fractions by cultures of the polymorphic fungus Aureobasidium pullulans. Carbohydr Polym 1997;32:307-14.

56. Yurlova NA, Hoog GS. A new variety of Aureobasidium pullulans characterized by exopolysaccharides structure, nutritional physiology and molecular features. Anton Leeuw J Microbiol 1997;72:141-7.

57. Kacurakova M, CapekP, Sasinkova V, WellnerN, EbringerovaA.FT-IR study of plant cell wall model compounds: Pectic polysaccharides and hemicellulose. Carbohydr Polym 2000;43:195-203.

58. Kacuráková M, Mathlouthi M. FTIR and laser-Raman spectra of oligosaccharides in water: Characterization of the glycosidic bond. Carbohydr Res 1996;284:145-57.

59. McIntyre DD, Vogel HJ. Nuclear magnetic resonance studies of homopolysaccharides related to starch. Starch Stärke 1991;43:69-76.

60. McIntyre DD, Vogel HJ. Structural studies of pullulan by nuclear magnetic resonance spectroscopy. Starch Stärke 1993;45:406-10.

61. Youssef F, Roukas T, Biliaderis CG. Pullulan production by a nonpigmented strain of Aureobasidium pullulans using batch and fedbatch culture. Process Biochem 1999;34:355-66.

62. Singh RS, Saini GK, Kennedy JF. Downstream processing and characterization of pullulan from a novel colour variant strain of Aureobasidium pullulans FB-1. Carbohydr Polym 2009;78:89-94.

How to cite this article:
Singh RS, Kaur N. Biochemical and molecular characterization of a new
pullulan producer Rhodosporidium paludigenum PUPY-06. J App Biol
Biotech. 2018;6(1):28-37. DOI: 10.7324/JABB.2018.60106

